\title{
COMPUTATIONAL MODELLING OF A TANGENTIALLY FIRED BOILER WITH DEPOSIT FORMATION PHENOMENA
}

\author{
Norbert J. Modliński* \\ Wroclaw University of Technology, Institute of Heat Engineering and Fluid Mechanics, Wybrzeże \\ Wyspiańskiego 27, 50-370 Wrocław, Poland
}

\begin{abstract}
Any complete CFD model of pulverised coal-fired boiler needs to consider ash deposition phenomena. Wall boundary conditions (temperature and emissivity) should be temporally corrected to account for the effects of deposit growth on the combustion conditions. At present voluminous publications concerning ash related problems are available. The current paper presents development of an engineering tool integrating deposit formation models with the CFD code. It was then applied to two tangentially-fired boilers. The developed numerical tool was validated by comparing it with boiler evaporator power variation based on the on-line diagnostic system with the results from the full CFD simulation.
\end{abstract}

Keywords: tangentially fired furnace, deposit formation, pulverised coal, CFD

\section{INTRODUCTION}

In recent years boiler performance and environmental concerns as well as utility maintenance issues have increased the use of computational fluid dynamics codes to investigate pulverised coal reactive flow characteristics in large scale boilers. Commercial codes such as Fluent or Code Saturne have been extensively applied to provide information on the complex phenomena including gas-solid flow, combustion and heat transfer (Belosevic et al., 2006; Asotani et al., 2008; Yin et al., 2003; Fan et al., 2001; Belosevis et al., 2008). These tools are then used to build boiler models customised with plant operational diagnostic data and experience. CFD models are tuned and validated by parametric testing studies.

A crucial part of power plant design and operation depends on the ash which unavoidably adheres to heat exchanging-surfaces, causing detrimental effects. Deposits produced during coal combustion have strong influence on the performance of power generating facilities. Slagging not only reduces thermal efficiency of a furnace, but also affects its integrity as a result of corrosion, erosion and impact on the bottom tubes (Lockwood and Lee, 1999). As deposit develops on a heat transfer surface, the insulating properties decrease the net heat transfer rate through the ash layer while also causing the surface temperature of the ash to increase with growing thickness.

Basic modelling assumptions do not take into account non-stationary ash deposition process occurring on combustion chamber walls and its impact on heat transfer. Any complete CFD model of pulverised coal-fired boiler should temporally correct wall boundary conditions (temperature and emissivity) as schematically shown in Fig. 1. Combustion conditions inside the furnace and deposit growth have a complex mutual dependence. 


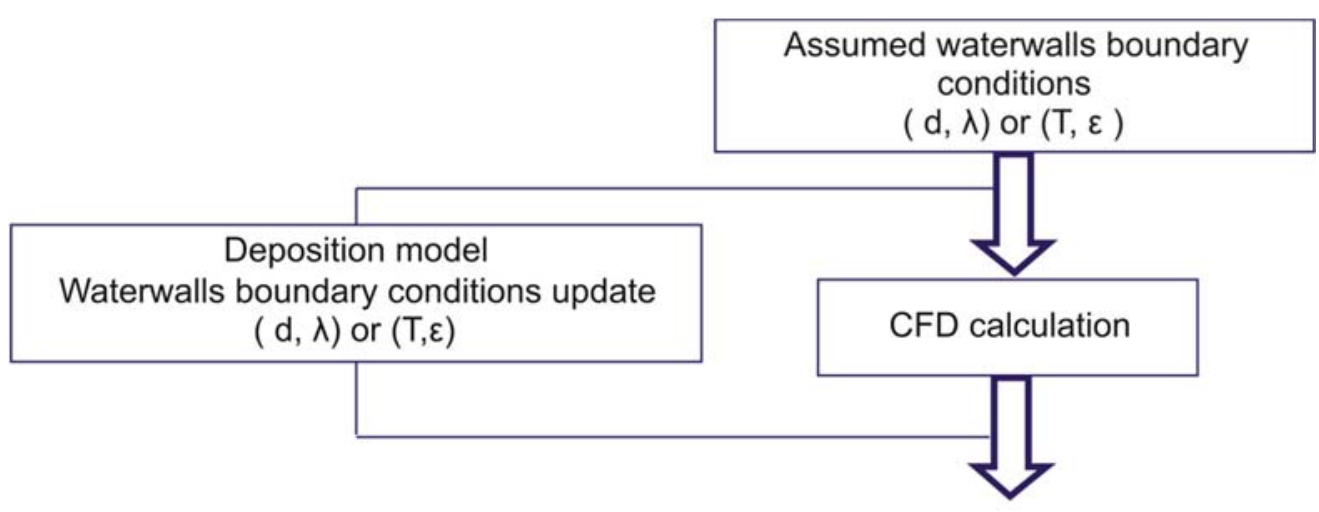

Fig. 1. Full CFD furnace simulations completed with deposition model

By implementation of ash behaviour models into CFD codes engineers are provided with a powerful tool to assess the impact of waterwall slagging on furnace performance. At present voluminous publications concerning ash related problems are available. They give a possibility to formulate physical and chemical processes including ash formation (prediction of particle size and composition distribution), transport, deposition rate, deposit growth and thermal properties into computer codes. Information on deposit growth in local areas and its impact on heat transfer can be provided by integration of the above programs with a 3D CFD boiler model.

The current paper presents development of an engineering tool integrating deposit formation models with the CFD code. It was then applied to two tangentially-fired boilers installed at the EDF CHP plant in Cracow (Poland) utilising bituminous coal. The first of them (OP-380) was retrofitted by replacing traditional jet burners with RI-JET2 swirl burners. This kind of solution is unique in power generation systems. The results have been compared to numerical simulation of OP-430 boiler equipped with conventional jet burners. Information appearing from the industry about lower corrosion rate and lower slagging of the OP-380 waterwalls was confirmed which is related to different aerodynamic characteristics. In-depth information on simulation of these boilers can be found in (Modliński, 2010).

In the previous research (Modliński, 2010) deposition phenomena were not investigated in detail. Only minor attention to the deposition phenomenon was given there and no experimental verification offered. The deposition model used did not consider any thermal effects which are presented in the current work. The developed numerical tool was validated by comparison with OP-380 boiler evaporator power variation based on the on-line diagnostic system with the results from the full CFD simulation.

\section{DEPOSIT FORMATION MODEL}

A number of particle transport or deposition mechanisms can be responsible for the build up of a deposit layer on the surfaces of furnace walls. The inertial impaction of fly ash particles in the growing deposit surfaces is most often the dominant slag formation process within the furnace (Ma et al., 2007). For a particle to deposit on a surface it must have sufficient momentum normal to the surface to penetrate the fluid layer next to it. For waterwalls and pendant super heaters, the inertial impaction rate is calculated by monitoring when a particle trajectory meets the surface.

Discrete phase trajectories are calculated using Lagrangian formulation and the coupling between the phases is introduced through particle sources of Eulerian gas-phase equations. Within the particle transport model, the mass flow of particles is represented by a number of trajectories that always represent a much larger number of actual particles. The dispersion of particles due to turbulence in the fluid phase was considered. 
Whenever a particle trajectory hits the wall, deposit flux is calculated from the assumption that the ratio of mass deposited by a particle to the total effective mass of the particle is equal to the sticking probability, which in fact represents probability of the expected mass to deposit from a large number of particles represented by the single particle.

Most mechanistic particle adhesion modelling approaches use the concept presented in (Walsh et al., 1990), which provides the basis for many research studies on deposit formation simulations (Lockwood and Lee, 1999; Degereji et al., 2012). The sticking probability of an impacting particle is determined as a function of the sticking probability of both the particle $\left(p_{\text {part }}\right)$ and the surface $\left(p_{\text {surf }}\right)$. Neglecting resuspension and other removing mechanisms:

$$
p_{\text {tot }}=p_{\text {part }}+\left(1-p_{\text {part }}\right) \cdot p_{\text {surf }}
$$

For silica rich particles an assumption has been made that the probability of a particle sticking to the surface is inversely proportional to its effective viscosity for viscosities higher than the critical viscosity. For viscosities lower than critical, the sticking probability is assumed to be unity (Walsh et al., 1990). The model heavily depends on the chosen critical viscosity value. Little consistency exists in the literature for choosing this value (Richter, 2003).

Richter showed a relation between critical viscosity and relative kinetic energy of the impacting particle, where kinetic energies are normalised with the kinetic energy of the smallest particle $\left(E_{\text {kinn }}\right)$.

$$
\log _{10}\left(\mu_{\text {critical }}\right)=-0.9699 \cdot \log _{10}\left(\frac{E_{\text {kin }}}{E_{\text {kin } 0}}\right)+5.5962
$$

This equation is a result of experimental investigations. The author used synthetic silica rich ashes (glass particles) and studied the sticking behavior on ceramic deposit probes. The measurements were performed with varying gas velocities, particle diameters and gas temperatures. This approach was employed in the current study.

In order to use the viscosity model discussed previously, a model describing the viscosity of ash is needed. To be useful for deposition modelling, ash viscosity must be described as a function of particle temperature and ash composition. In the current paper a model proposed in (Browning et al., 2003) is used. The model is a function of mole fractions of $\mathrm{Si}, \mathrm{Al}, \mathrm{Ca}, \mathrm{Fe}, \mathrm{Mg}, \mathrm{Na}, \mathrm{K}, \mathrm{Mn}, \mathrm{Ti}, \mathrm{S}$ and provides improvements over other models in matching experimental data.

\section{DEPOSIT THERMAL PROPERTIES MODEL}

Thermal energy is transferred to a deposit surface by both radiation and convection with convection normally being of secondary importance in the furnace region. Heat is then conducted through the deposit layer and tube wall and transferred to the cooling fluid. The properties of the deposit with the greatest impact on heat transfer are thermal conductivity and surface emittance. These properties are dependent upon ash deposit morphology, chemical composition and temperature.

The thermal properties of accumulated ash layers were described using the model proposed in (Cundick et al., 2007). This model consists of four regimes and accounts for the change in deposit morphology as it grows. As the deposit surface temperature increases, the ash can take on particulate, sintered, slag and frozen slag forms. The gradation of deposit morphology was achieved by introducing transition temperatures at each regime boundary (effective "sintering" and "slagging" temperatures). Averaged properties typical for each layer are given in (Cundick et al., 2007). Values for these properties including thermal conductivity, density and emittance were treated as constants throughout each regime (Table 1). 
Table 1. Parameters of deposit thermal properties (Cundick et al., 2007).

\begin{tabular}{|c|c|c|}
\hline Variable & Value & Units \\
\hline$T_{\text {sint }}$ & 1300 & $\mathrm{~K}$ \\
\hline$T_{\text {slag }}$ & 1600 & $\mathrm{~K}$ \\
\hline$k_{\text {part }}$ & 0.4 & $\mathrm{~W} /\left(\mathrm{m}^{2} \cdot \mathrm{K}\right)$ \\
\hline$k_{\text {sint }}$ & 1 & $\mathrm{~W} /\left(\mathrm{m}^{2} \cdot \mathrm{K}\right)$ \\
\hline$k_{\text {slag }}$ & 5 & $\mathrm{~W} /\left(\mathrm{m}^{2} \cdot \mathrm{K}\right)$ \\
\hline$\rho_{\text {part }}$ & 800 & $\mathrm{~kg} / \mathrm{m}^{3}$ \\
\hline$\rho_{\text {sint }}$ & 1200 & $\mathrm{~kg} / \mathrm{m}^{3}$ \\
\hline$\rho_{\text {slag }}$ & 2000 & $\mathrm{~kg} / \mathrm{m}^{3}$ \\
\hline$\varepsilon_{\text {part }}$ & 0.7 & - \\
\hline$\varepsilon_{\text {sint }}$ & 0.5 & - \\
\hline$\varepsilon_{\text {slag }}$ & 0.9 & - \\
\hline
\end{tabular}

A balance between the radiative heat flux from the flame and the conductive flux throughout the deposit describes the variation of the deposit surface temperature with the deposit growth. A complex coupling exists between the deposit structure and surface temperature according to the following equation:

$$
q_{\text {total }}=\frac{T_{\text {surf }}-T_{\text {cool }}}{\sum_{i}^{N} \frac{\Delta x_{i}}{k_{i}}}=\varepsilon_{\text {surf }} \sigma\left(T_{f}{ }^{4}-T_{\text {surf }}{ }^{4}\right)+h \cdot\left(T_{f}-T_{\text {surf }}\right)
$$

In addition to thermal conductivity, emittance and heat transfer rates depend mainly on deposit thickness. The deposit thickness, however, depends on the temperature distribution in the deposit which in turn is governed by the thermal conductivity and the heat flux to the deposit surface.

The growing deposit does not influence the basic flow. It does not change computational domain geometry. Only the thermal transport sub-model couples code Fluent with general deposition model by implementation of surface temperature and emittance information into Fluent. Since the rate of thermal transport is much greater than the rate of energy storage for layers of ash, a quasi-stationary approach is appropriate. In the specific time step $(\Delta t)$ thermal model solves the steady-state thermal transport through the deposit for constant deposit layers. Using the deposit surface temperature as the boundary condition, Fluent iterates with energy equation and provides the total heat flux absorbed by the surface to the thermal sub-model. The surface temperature is updated based on the given heat flux and passed as a boundary condition to Fluent again. After a sufficient number of iterations when surface temperature and heat flux values are stabilised, a new set of particles is injected in a new time step. After another layer of ash is added to the deposit, the process repeats itself.

Once the solution converges in a particular time increment, the model accounts for sintering of a particulate layer and slagging of a sintered layer according to newly formed temperature profile across the deposit.

\section{RESULTS}

The focus of the current paper is the deposit formation model incorporated with a boiler CFD code. Model predictions have been presented for both boilers. Impaction rates on heat transfer surface and influence on heat exchange degradation in the combustion chamber was estimated for four hours, full- 
load boiler operation without soot-blowing activity. Fig. 2 shows ash impaction $\left[\mathrm{kg} /\left(\mathrm{m}^{2} \cdot \mathrm{s}\right)\right]$, deposit thickness $[\mathrm{m}]$, deposit thermal resistance $\left[\mathrm{m}^{2} \mathrm{~K} / \mathrm{W}\right]$, surface temperature $[\mathrm{K}]$ comparison between OP430 and OP-380. Results have confirmed the industry reports about lower slagging of the OP-380 waterwalls. The primary mode of particle transport to heat-transfer surface is inertial impaction. We can conclude that deposits grow rapidly at points whose particles impact regularly. The growth rate of deposits is proportional to the impact probability. The figure demonstrates that different aerodynamic characteristics inside the furnaces have influence on deposit formation. Big differences in ash impaction patterns can be observed. In OP-430 most deposition occurs in burner belt, where the flue gas temperature causes a low viscosity of ash forming compounds, resulting in a high sticking probability of the particles. In OP-380, regions above OFA ports are more susceptible to slagging. In both boilers, increased deposit formation around the OFA ports can be attributed to injected air which generates recirculation zone. Particles are captured in these zones and directed against the wall. This leads to high impaction rate in those locations. The deposit thickness distribution is not exactly the same as the ash impaction pattern because deposit formation and growth is affected by the temperature profile across the deposit layer, which changes its morphology.

OP-380 retrofitting by installing RI-JET2 burners was accompanied by another modification of furnace corners in order to reduce slagging.
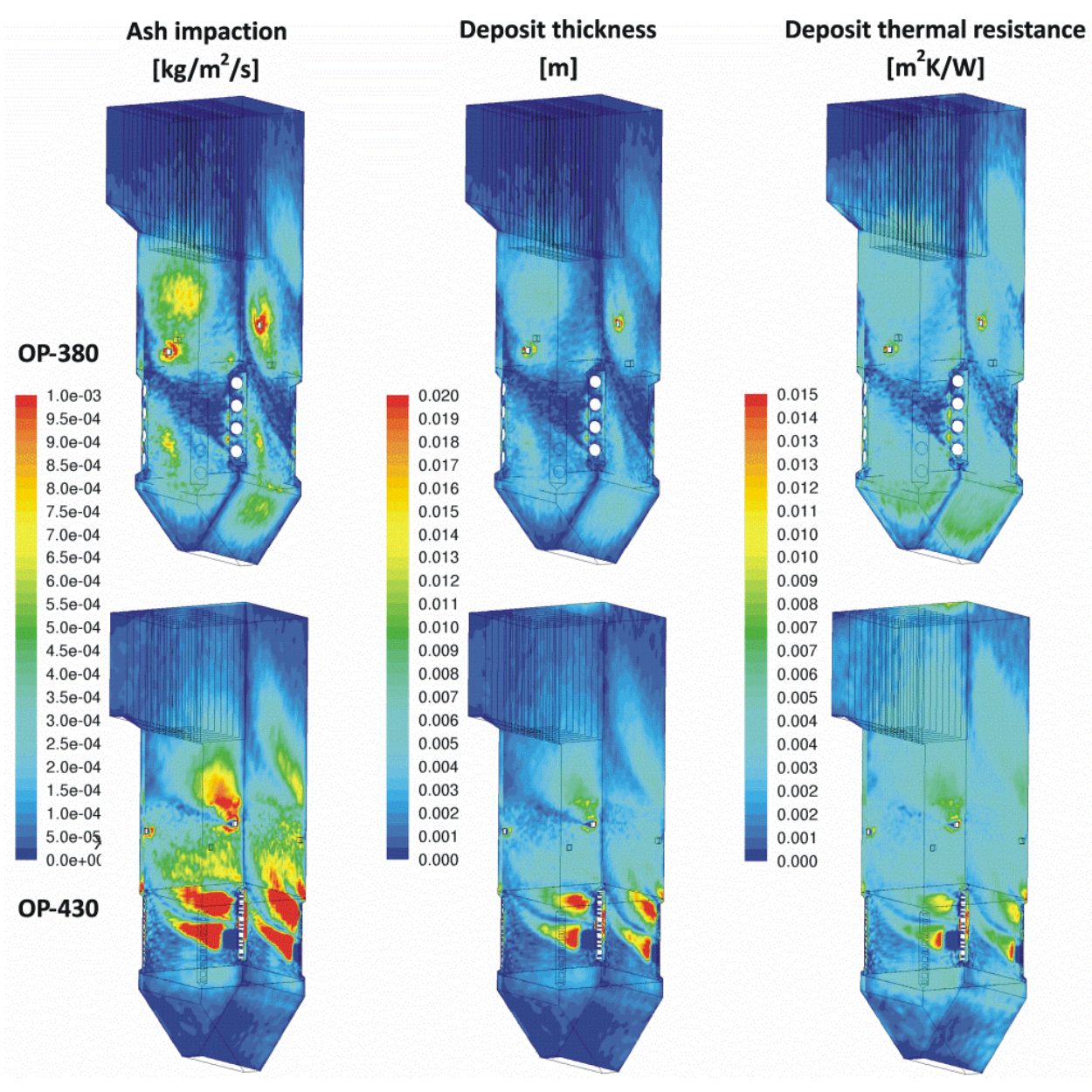

Surface temperature

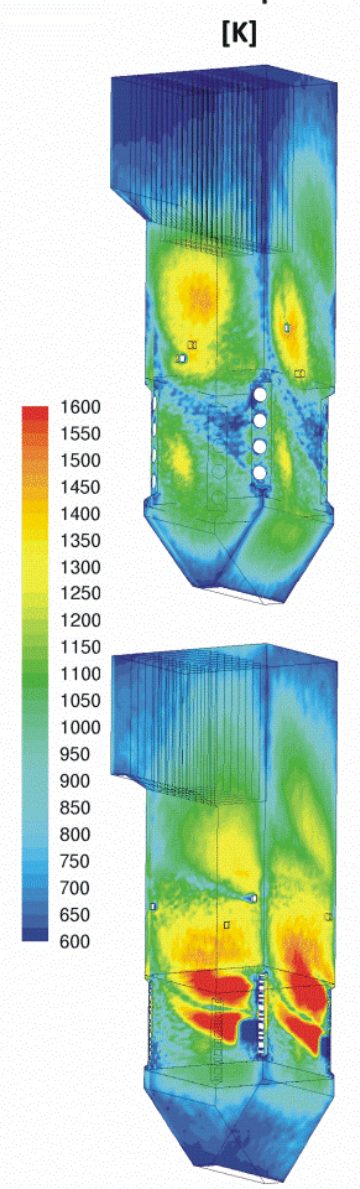

Fig. 2. Ash impaction $\left[\mathrm{kg} /\left(\mathrm{m}^{2} \cdot \mathrm{s}\right)\right]$, deposit thickness $[\mathrm{m}]$, deposit thermal resistance $\left[\mathrm{m}^{2} \mathrm{~K} / \mathrm{W}\right]$, surface temperature $[\mathrm{K}]$ comparison between OP-380 (top figures) and OP-430 (bottom figures). 


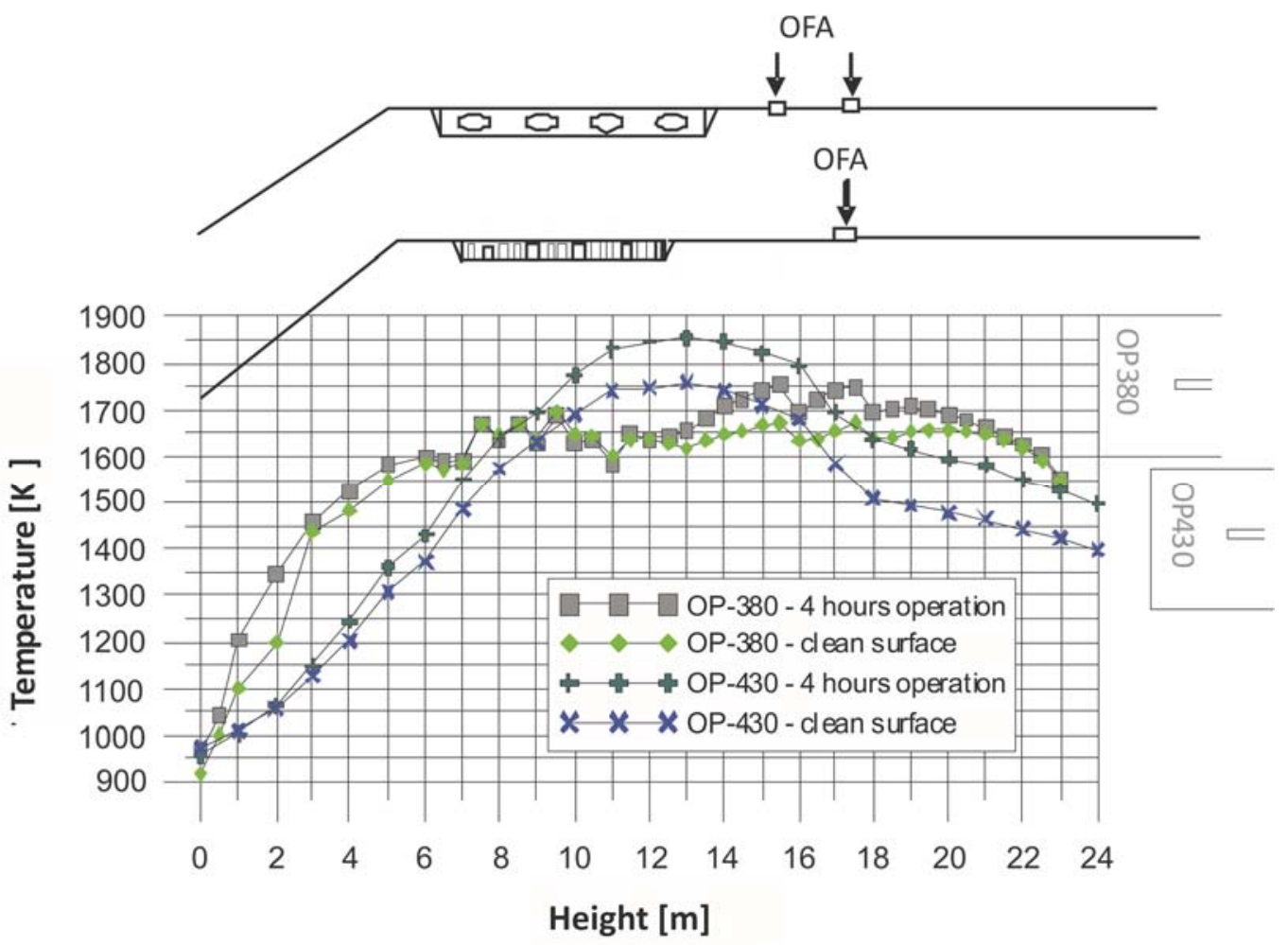

Fig. 3. Comparison of average temperatures in horizontal planes along the furnaces height.

Vertical distance between burner levels was increased to reduce the burner zone heat release rate as demonstrated in Fig. 3. It can be seen that the average temperatures in the horizontal planes along the burner height are significantly lower for OP-380 in comparison to OP-430. As the deposit grows, the thermal resistance increases and surface temperature rises. As a result the temperature in the furnaces increases in comparison to clean surface cases.

\section{VALIDATION}

The deposition model was validated by comparison with the calculated evaporator power of OP-380 boiler with values determined from the on-line measuring system. The general system collects data from different unit measurement subsystems. Over 1000 analogue variables (pressure, temperature, flow rates, power, voltage, etc.) are acquired. They are kept in archive with three second sampling rate.

The thermal power of evaporator was calculated from the following equation:

$$
Q_{\text {evap }}=D_{\text {evap }} \cdot\left(i, i_{\mathrm{ECO}}\right)=D_{\text {evap }} \cdot\left(h^{\prime \prime}\left(p_{\text {sat }}\right)-h\left(t_{\mathrm{ECO}}, p_{\mathrm{ECO}}\right)\right)
$$

where $h^{\prime \prime}(p)$ and $h(t, p)$ are functions from numerical steam tables (www.iapws.org, IAPWS-IF97) for saturation enthalpy corresponding to dryness factor equal to 1 and enthalpy as a function of temperature and pressure. Values of $D_{\text {evap }}, p_{\text {sat }}, t_{\mathrm{ECO}}, p_{\mathrm{ECO}}$ have been measured. Analysis data of one hour measurement has shown measurement uncertainty of evaporator power of around $1 \%$.

Fig. 4. shows a comparison of evaporator thermal power calculations with measurements. Three computation tests were planned, each having 13 calculation samples. Each test stands for four hours of boiler operation. An assumption was made that after each four-hour interval, soot blowers are activated with $100 \%$ efficiency. Measurement data shows evaporator power fluctuations ranging from 120 to 140 MW, whereas calculation results range from 110 to $140 \mathrm{MW}$. 


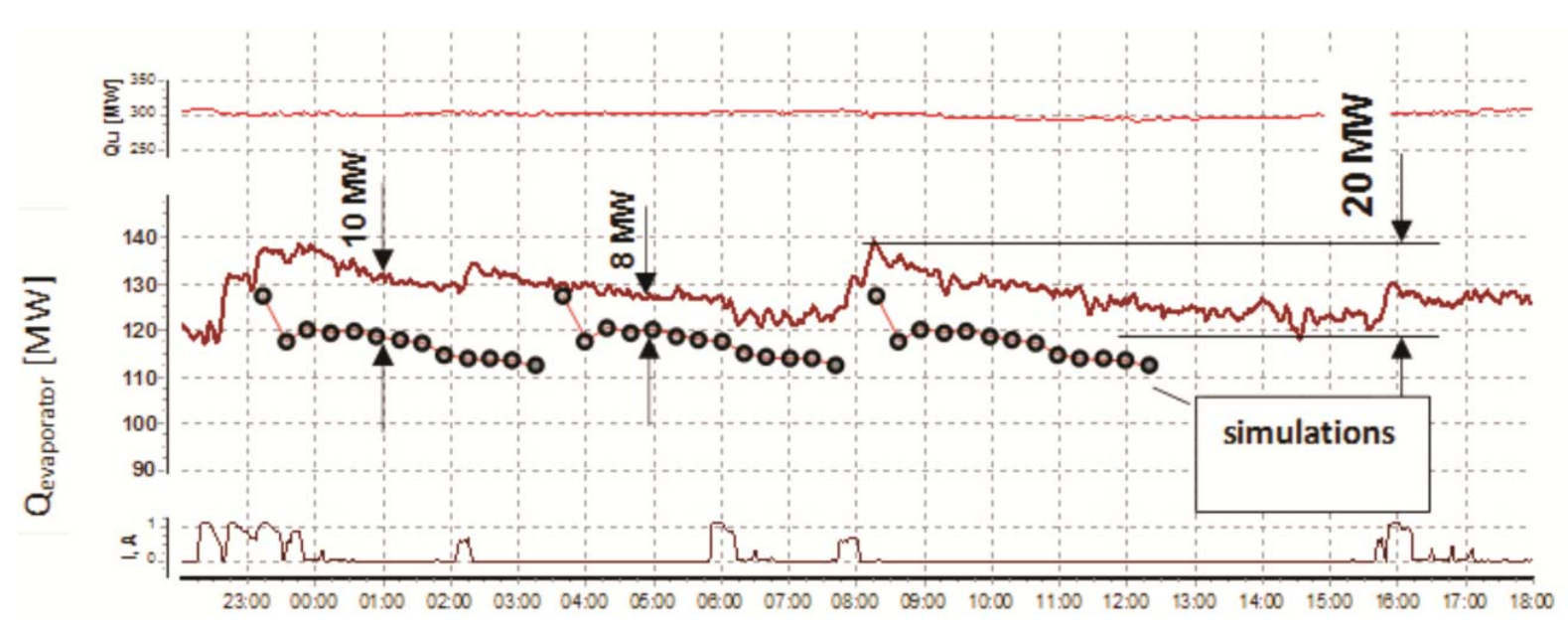

Fig. 4. Comparison of evaporator thermal power [MW] calculations with measurements

\section{CONCLUSIONS}

Model predictions have been presented for OP-380 and OP-430 boilers. Impaction rates on heat transfer surface and influence on heat exchange degradation in the combustion chamber was estimated for four hours, full-load boiler operation without soot-blowing activity. Results have confirmed the industry reports about lower slagging of the OP-380 waterwalls.

The average error of evaporator power calculations is about $8 \%$. When neglecting the sudden drop in the beginning of the simulations, which is related to deposit formation on perfectly clean surface of the evaporator, the qualitative agreement with measurements is very satisfactory. The rate of power decrease in the real boiler and obtained in the computations is very similar. It results in about $10 \mathrm{MW}$ drop after 4 hours of operation.

The developed tool can be used to assess the impact of slagging process on plant performance for both design and operational purposes.

\section{SYMBOLS}

$\begin{array}{ll}D & \text { mass flow rate, } \mathrm{kg} / \mathrm{s} \\ E & \text { kinetic energy (unit?) } \\ h & \text { fluid side heat transfer coefficient, } \mathrm{W} /\left(\mathrm{m}^{2} \cdot \mathrm{K}\right) \\ k_{l} & \text { mean thermal conductivity, } \mathrm{W} /(\mathrm{m} \cdot \mathrm{K}) \\ p & \text { particle sticking probability } \\ T & \text { temperature, transition temperature, } \mathrm{K} \\ t & \text { water, steam temperature, } \mathrm{K} \\ q & \text { heat flux, } \mathrm{W} / \mathrm{m}^{2} \\ Q & \text { power, } \mathrm{W}\end{array}$

\section{Greek symbols}

$\begin{array}{ll}\Delta x & \text { thickness, } \mathrm{m} \\ \varepsilon & \text { emittance } \\ \propto & \text { dynamic viscosity, Pa s } \\ \rho & \text { density, } \mathrm{kg} / \mathrm{m}^{3} \\ \sigma & \text { Stefan Bolztman constant }\left(5.67 \times 10^{-8} \mathrm{~W} /\left(\mathrm{m}^{2} \cdot \mathrm{K}^{4}\right)\right.\end{array}$




$\begin{array}{ll}\text { Subscripts } & \\ \text { cool } & \text { denotes coolant } \\ \text { critical } & \text { denotes critical } \\ \text { evap } & \text { evaporator } \\ \text { ECO } & \text { Economiser } \\ f & \text { denotes flame } \\ i & \text { denotes layer i } \\ \text { kin } & \text { denotes kinetic } \\ \text { kin0 } & \text { denotes kinetic in reference to the smallest particle } \\ \text { part } & \text { denotes particle, particulate } \\ \text { sat } & \text { saturation } \\ \text { sint } & \text { denotes sintering } \\ \text { slag } & \text { denotes slagging } \\ \text { surf } & \text { denotes surface } \\ \text { tot } & \text { denotes total }\end{array}$

\section{REFERENCES}

Asotani T., Yamashita T., Tominga H. Uesugi Y., Itaya Y., Mori S., 2008. Prediction of ignition behavior in a tangentially fired pulverized coal boiler using CFD. Fuel, 87, 482-490. DOI:10.1016/j.fuel.2007.04.018.

Belosevic S., Sijercic M., Oka S., Tucakovic D., 2006. Three-dimensional modeling of utility boiler pulverized coal tangentially fired furnace. Int. J. Heat Mass Transfer, 49, 3371-3380. DOI: 10.1016/j.ijheatmasstransfer.2006.03.022.

Belosevic S., Sijercic M., Tuckovic D., Crnomarkovic N., 2008. A numerical study of a utility boiler tangentiallyfired furnace under different operating conditions. Fuel, 87, 3331-3338. DOI: $10.1016 / \bar{j} . \overline{f u e l} .2008 .05 .014$.

Browning G., Bryant G., Hurst H., Lucas J., Wall T., 2003. An empirical method for the prediction of coal ash slag viscosity. Energy Fuels, 17, 731-737. DOI: 10.1021/ef020165o.

Cundick D., Blanchard R., Maynes D., Tree D., Baxter L., 2007. Thermal transport to a reactor wall with a time varying ash layer. 5th US Combustion Meeting, San Diego, CA, USA, 2007.

Degereji M., Ingham D., Ma L., Pourkashanian M., Williams A., 2012. Prediction of ash slagging propensity in a pulverized coal combustion furnace. Fuel, 101, 171-178. DOI: $10.1016 /$ j.fuel.2010.12.038.

Fan J., Qian L., Ma Y., Sun P., Cen K., 2001. Computational modeling of pulverized coal combustion processes

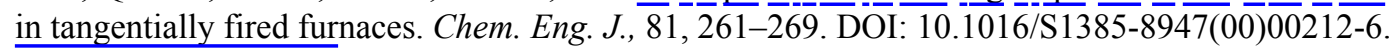

Lockwood F., Lee F., 1999. Modeling ash deposition in pulverized coal-fired boilers. Prog. Energy Combust. Sci., 25, 117-132. DOI:10.1016/S0360-1285(98)00008-2.

Ma F., Iman P., Lu R., Sears L., Kong A., Rokanuzzaman D., Mccollor S., Benson S., 2007. A comprehensive slagging and fouling prediction tool for coal-fired boilers and its validation/application. Fuel Process. Technol., 88, 1035-1043. DOI: $10.1016 /$ j.fuproc.2007.06.025.

Modliński N., 2010. Computational modeling of a utility boiler tangentially-fired furnace retrofitted with swirl burners. Fuel Process. Technol., 91, $\overline{601-1608 .}$ DOI: 10.1016/j.fuproc.2010.06.008.

Richter S., 2003. Numerische Simulation der Flugashdeposition in kohlestaubgefeuerten Dampferzeugern, Fortschritt-Berichte VDI, Reihe 6, Nr.501, VDI Verlag.

Yin C., Rossendahl L., Condra T., 2003. Further study of the gas temperature deviation in large-scale tangentially-fired boilers. Fuel, 82, 1127-1137. DOI: $10.1016 / \mathrm{S} 001 \overline{6}-2361(02) 00418-0$.

Walsh P., Sayre A., Loehden D., Monroe L., Beer J., Sarofim S., 1990. Deposition of bituminous coal ash on an isolated heat exchanger tube: effects of coal properties on deposit growth. Prog. Energy Combust. Sci., 16, $327-$ 346. DOI: 10.1016/0360-1285(90)90042-2. 